\title{
MULTI-COMPONENT NITRATED ION-PLASMA Ni-Cr COATING
}

\author{
V. Nadtoka ${ }^{1 *}$, M. Kraiev ${ }^{1}$, A. Borisenko ${ }^{2}$, V. Kraieva ${ }^{3}$ \\ ${ }^{I}$ Yuzhnoye State Design Office, Dnipro, Ukraine \\ ${ }^{2}$ Z.I. Nekrasov Iron \& Steel Institute of the NAS of Ukraine, Dnipro, Ukraine \\ ${ }^{3}$ Dniprovsky National University of Railway Transport, Dnipro, Ukraine \\ *e-mail:vnadtoka@i.ua
}

\begin{abstract}
Method for ion-plasma deposition is applied for covering of heat-resistant Ni-Cr alloy XH78T. Coating deposition is performed under nitrogen gas atmosphere at the pressure from $3 \times 10^{-5}$ to $1 \times 10^{-2}$ Torr. The nitrogen content in the coating is reached up to $2,7 \%$. Nitrated coatings with a thickness of 184-222 $\mu \mathrm{m}$ is obtained without embrittlement and with a uniform distribution of microhardness. The effect of the nitrogen pressure in a vacuum chamber on the structure of the coatings, which changes from homogeneous to columnar with conical crystallites, is presented. Nitration increases microhardness of the coatings from 3669 to $7575 \mathrm{HV}$, the wear resistance of the coatings increases by 6-8 times. The received coatings can be used to increase the durability of metallurgical equipment parts.
\end{abstract}

Keywords: coating, nichrome, nitration, microhardness, wear resistance.

Received 15.06.2021; Received in revised form 25.07.2021; Accepted 15.08.2021

\section{Introduction}

High-strength coatings are used to protect rubbing parts in many industries. In metallurgy, friction conditions can be complicated by the operation of parts when exposed to high temperatures. Under these conditions, the coating must have a set of properties: heat resistance, strength, wear resistance and adhesion. The known one- and two-component coatings $\mathrm{Ni}, \mathrm{Cr}$, Ni-Cr, Ni-Co, Fe-Ni, being heat-resistant, do not provide a high level of strength. The hardness (HV) of these coatings is in the range of 1000-2000 MPa [1-3]. Coatings with carbides, nitrides and borides in their structure have increased heat resistance and the highest level of strength. Hardness of carbides - $10 \mathrm{GPa}$, nitrides - $30 \mathrm{GPa}$, borides $70 \mathrm{GPa}$ [4]. But their disadvantage is high fragility, so the coating thickness does not exceed 5 microns. For metallurgical equipment, it is relevant to apply heat-resistant coatings with a thickness from tenths of a millimeter to several millimeters. This increases the level of strength and wear resistance, which determines the life of the part.

Nitration is a suitable way to protect the surface of parts operating at temperatures up to $600{ }^{\circ} \mathrm{C}$, which is consistent with the operating conditions of metallurgical equipment. The process takes place in an atmosphere of nitrogen gas, safe for workers and environmentally friendly. The ion-plasma method of coating in a gaseous nitrogen atmosphere has advantages over a purely gaseous one: significantly lower energy consumption, higher energy of particles bombarding the surface, which reduces the duration of the technological cycle; controllability, stability and predictability of the final processing parameters, their uniformity over the surface [5]. As a result of nitration, interstitial solutions are formed or nitride phases are precipitated. The bulk of research [5-7] is aimed at obtaining high-strength, but thin nitride coatings. Dissolution of nitrogen in $\mathrm{Cr}-\mathrm{Ni}$ alloys significantly increases their strength and stabilizes the structure [8]. Based on this, it becomes possible to create heat-resistant and relatively thick coatings with a high level of strength.

\section{Material and Methods}

The material of the coatings was XH78T nichrome. The coatings were applied by ionplasma deposition. For nitration the coatings, nitrogen gas was supplied to the working area of the vacuum chamber with a constant pressure in the chamber. The pressure in the vacuum chamber without nitrogen addition was $3 \times 10^{-5}$ Torr. During nitration, the pressure in the vacuum chamber was gradually increased to $1 \times 10^{-2}$ Torr.

Chemical analysis of the cathode was performed with an ElvaX ProSpector X-ray 
fluorescence spectrometer.

The structure and chemical analysis of the coatings were studied on a SUPRA 40 WDS scanning electron microscope manufactured by Carl Zeiss (Germany) using a Si-Li energy dispersive characteristic X-ray spectrometer (EDS) manufactured by Oxford Instruments (Great Britain).

The strength of the coatings was determined by measuring the Vickers microhardness on a ПMT-3 hardness tester. Load value $100 \mathrm{~g}$.

The wear resistance of the coatings was investigated by abrasion on fine-grained abrasive paper P-800 with a grain size of $20,8-22,8 \mu \mathrm{m}$. Used grinding and polishing machine POLYTOUCH $2 \mathrm{H}$ (Italy) with regulation of the rate of abrasion and pressure of the sample to the abrasive surface.

\section{Results and discussion}

Nichrome coatings with a thickness of 184-222 $\mu \mathrm{m}$ were applied by the ion-plasma method. The chemical composition of the used cathode and the resulting coatings are shown in Table 1.

Content of chemical elements in alloy XH78T and its coatings, \% (wt.)

Table 1

\begin{tabular}{|l|c|c|c|c|c|c|c|}
\hline & $\mathrm{Ni}$ & $\mathrm{Cr}$ & $\mathrm{Ti}$ & $\mathrm{Mn}$ & $\mathrm{Fe}$ & $\mathrm{Si}$ & $\mathrm{N}$ \\
\hline Cathode & 77,90 & 19,09 & 0,29 & 0,28 & 0,61 & 1,03 & - \\
\hline Coating without nitration, $\mathrm{P}=3 \times 10^{-5}$ Torr & 73,55 & 22,10 & 0,15 & 0,06 & 0,49 & 0,03 & - \\
\hline Coating with nitration, $\mathrm{P}=1 \times 10^{-3}$ Torr & 73,80 & 21,42 & 0,15 & 0,49 & 0,48 & 0,23 & - \\
\hline Coating with nitration, $\mathrm{P}=5 \times 10^{-3}$ Torr & 69,59 & 20,62 & 0,21 & 0,49 & 0,51 & 0,27 & 1,92 \\
\hline Coating with nitration, $\mathrm{P}=1 \times 10^{-2}$ Torr & 68,58 & 22,35 & 0,19 & 0,62 & 0,51 & 0,26 & 2,69 \\
\hline
\end{tabular}

The nichrome coating has a reduced nickel content $(73,6 \%$ versus $77,9 \%)$, but an increased chromium content $(22.1 \%$ versus $19.1 \%)$ compared to the original composition of the sputtered cathode. When nitrogen is supplied and the pressure in the vacuum chamber is increased to $1 \times 10^{-2}$ Torr, the amount of nickel is reduced to $68.6 \%$. With an increase in the nitrogen pressure in the chamber, the mass fraction of manganese and silicon in the coating increases, their amount is within the range of the grade composition of nichrome. No logical change in the chromium content has been established. The nitrogen content in the coating was not detected at its minimum pressure in the vacuum chamber of $1 \times 10^{-3}$ Torr. Subsequently, as the pressure in the chamber increases, the nitrogen content in the coating increases to $2.7 \%$. The distribution of elements in the coatings is even in the longitudinal and transverse directions.

The microhardness of the nichrome coating is 3669 HV (Fig. 1a).

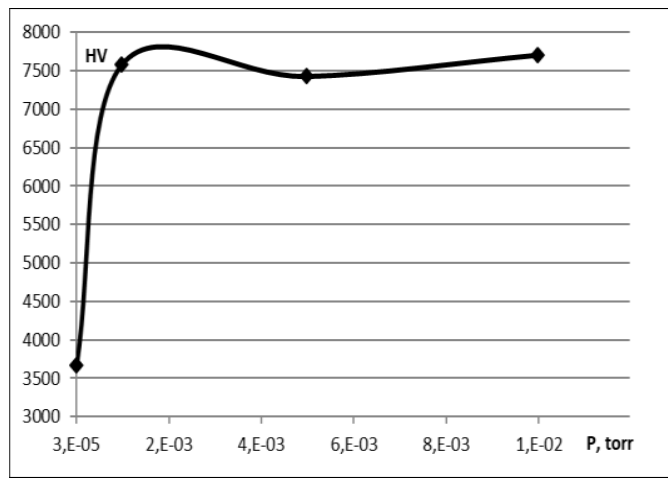

a

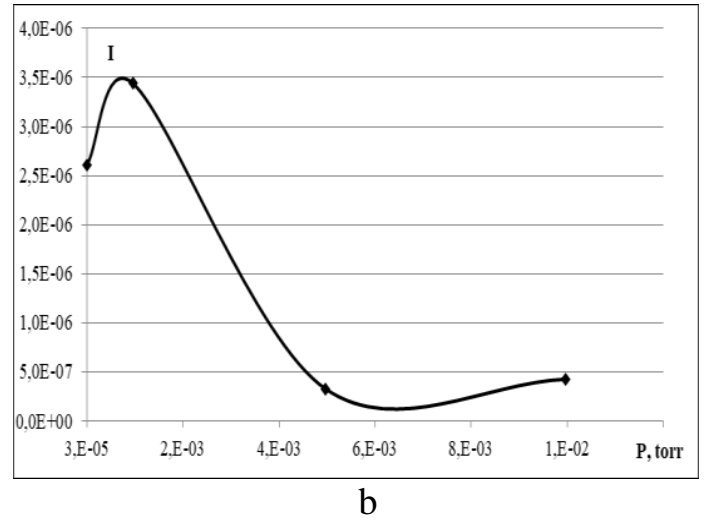

b

Fig. 1. Microhardness (a) and wear rate (b) of nichrome coatings at different nitrogen pressures 
With the addition of nitrogen $\left(\mathrm{P}=1 \times 10^{-3}\right.$ Torr $)$ to the vacuum chamber, the coating hardness increases sharply to $7575 \mathrm{HV}$, i.e. 2 times, but with a further increase in its concentration, the increase in hardness is no longer observed. With increasing strength, the wear rate of coatings I decreases (Fig. 1b). The I values are calculated as the ratio of absolute linear wear to the friction path. I decreases $6-8$ times at a nitrogen pressure not lower than $5 \times 10^{-3}$ Torr.

The nichrome coating has a uniform dense structure without the formation of a grain structure visible with a scanning electron microscope (Fig. 2a).

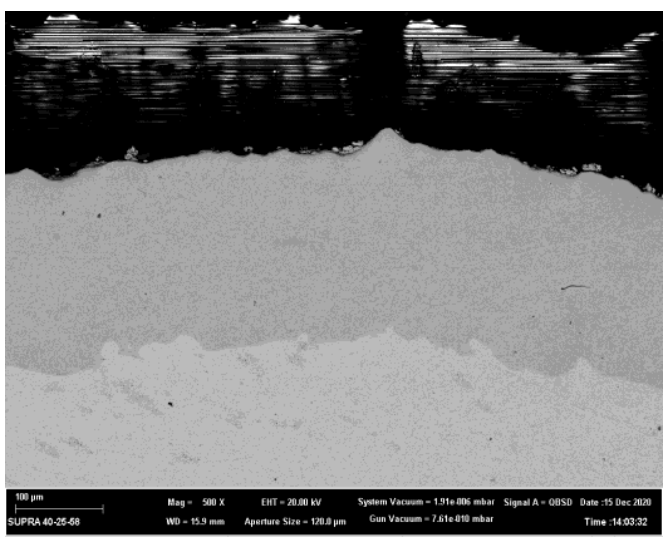

a

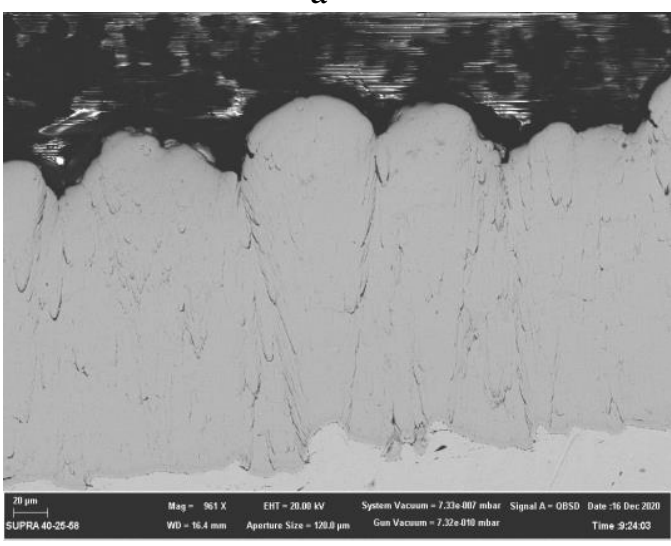

C

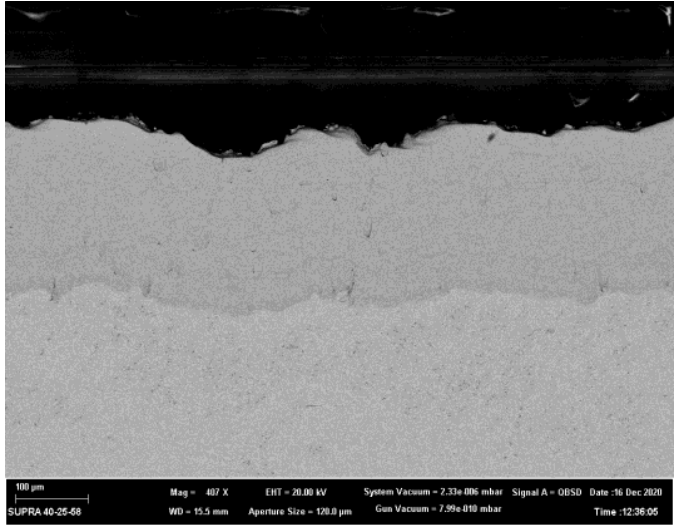

b

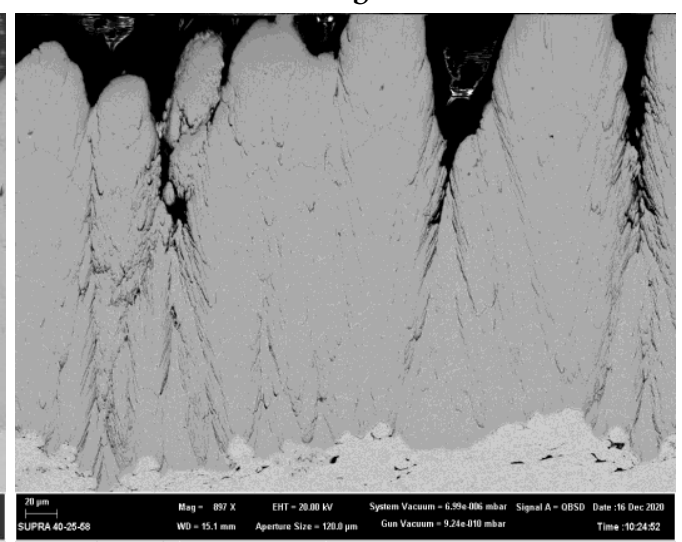

d

Fig. 2. Structure of nichrome coatings at pressure $P=3 \times 10^{-5}$ Torr (a), $P=1 \times 10^{-3}$ Torr (b), $\mathrm{P}=5 \times 10^{-3}$ Torr $(\mathrm{c}), \mathrm{P}=1 \times 10^{-2}$ Torr $(\mathrm{d})$

Nitration changes the structure of the coatings. With increasing nitrogen pressure in the vacuum chamber, the formation of pores (Fig. 2b), columnar grains (Fig. 2c) and conical crystallites separated by voids (Fig. 2d) is observed. The reason for this may be a decrease in the surface mobility of the deposited atoms due to an increase in the nitrogen pressure in the chamber [9].

\section{Conclusions}

Ion-plasma deposition allows the application of multicomponent coatings of nichrome XH78T with their simultaneous nitration.

Nitration affects the chemical composition of the coating, its structure, strength and wear resistance. 
Due to the dissolution of nitrogen in nichrome, it is possible to create thick (about $200-250 \mu \mathrm{m})$ coatings with a high hardness of $\sim 7500 \mathrm{HV}$ and $6-8$ times better wear resistance. With ion-plasma deposition of nichrome, the optimal nitrogen pressure in the vacuum chamber is within $5 \times 10^{-3}$ Torr.

\section{Acknowledgments}

We would like to express our gratitude for participation in the work of V.F. Bezugly, I.M. Leiter, I.V. Taranets.

\section{References}

1. Borisov, Y. Development of electric-arc pseudoalloy coatings for the strengthening of copper walls of molds / Y. Borisov, N. Vigilianska, I. Demianov, O. Grishchenko // Eastern-European Journal of Enterprise Technologies. - 2018. - No. 3. - P. $6-14$.

2. Spyros, K. Unique coating technology for superior mould wear resistance and product quality / K. Spyros // MPT Metallurgical Plant and Technology. - 2017. - No. 2. - P. $38-41$.

3. Liu, Y. Microstructure and Properties of Ni-Co Composite Cladding Coating on Mould Copper Plate / Y. Liu, Y. Liu, Y. Gao, C. Dong, S. Wang // Materials. - 2019; Vol. 12, No. 17:2782.

4. Zhang, S. Toughening of hard nanostructural thin films: a critical review / S. Zhang, D. Sun, Y. Fu, H. Du // Surface and Coatings Technology. - 2005. - Vol. 198, No. 1-3. - P. $2-8$.

5. Pastukh, I.M. Nitridin with glow discharge: state and prospects / I.M. Pastukh, G.N. Sokolova, N.V. Luk'januk // Problems of Tribology. - 2013. - № 3. - P. 18 - 22.

6. Beresnev, V.M. Coatings obtained by deposition of refractory compounds from flows of vacuum-arc metallical plasma / V.M. Beresnev, V.T. Tolok, V.I. Gritsenko // Physical surface engineering. - 2003. - Vol. 1, No. 3-4. - P. 237 - 257.

7. Tabakov, V.P. Formirovanie iznosostojkikh ionno-plazmennykh pokrytij rezhushchego instrumenta / V.P. Tabakov. - M.: Mashinostroenie, 2008. - 314 p.

8. Shejko, I. V. Legirovanie stalej i splavov azotom iz dugovoj plazmy: teoriya i praktika (Obzor. Chast' 1) / I.V. Shejko, G.M. Grigorenko, V.A. Shapovalov // Sovremennaya ehlektrometallurgiya. - 2016. - № 1 (122). - P. 32 - 37.

9. Mrochek, Zh.A. Plazmenno-vakuumnye pokrytiya [Text] / Zh.A. Mrochek, A.K. Vershina, S.A. Ivashchenko. - Mn.: UP «Tekhnoprint», 2004. - 368 p. 